\title{
Hard times and falling fertility in the United States
}

\author{
Philip N. Cohen \\ University of Maryland, College Park
}

Dorcid.org/0000-0003-2839-3144

\begin{abstract}
Recent reports have suggested that falling fertility in the US since the 2008 recession is being driven by women with advantaged status in the labor market taking advantage of career opportunities. This paper takes issue with that conclusion. Although high incomes are associated with lower fertility in general, both in the cross section and over time (within and between countries), economic crises also lead to lower fertility. I offer a new descriptive analysis using data from the American Community Survey for 2000-2019. In the U.S. case, the fertility decline was widespread after the 2008 recession, but most concentrated among younger women. Although women with above average education have long had lower birth rates, the analysis shows that birth rates fell most for women in states with higher than average unemployment rates, especially among those with below average education. This is consistent with evidence that birth rates are falling, and births delayed, by economic insecurity and hardship.
\end{abstract}

This is an unreviewed working paper. I welcome comments and suggests.

Research materials for this paper are available at: osf.io/xsvtb/ 


\section{Introduction}

A New York Times article by Sabrina Tavernise et al. was titled, "Why American Women Everywhere Are Delaying Motherhood" (Tavernise et al. 2021). Although it did not provide a simple answer to the question, it did offer this: "As more women of all social classes have prioritized education and career, delaying childbearing has become a broad pattern among American women almost everywhere." And it included a figure showing birth rates falling faster in counties with faster job growth. Reading that article, the writer Jill Filipovic concluded, "the women who are driving this downturn [in fertility] are those who have the most advantage and the greatest range of choices, and whose prospects look brightest" (Filipovic 2021). This paper takes issue with that conclusion.

Clearly, one driver of delayed childbearing is the desire to maximize career opportunities, but there is also the weight of uncertainty and insecurity, especially regarding the costs of parenting. Filipovic (2021) also wrote, "Children? In this economy?" These two tendencies appear to generate opposing economic effects: A strong economy gives mothers more rewarding opportunities that childrearing threatens (reducing fertility), while also providing greater economic security to make parenting more affordable and desirable (increasing fertility). These two pathways for economic influence on fertility trends are not easily separable in research - or necessarily exclusive in personal experience. In what follows I will briefly situate falling US fertility in the wider historical and global context, and then offer a descriptive analysis of the US trend in births from 2000 to 2019, focusing on relative education and state unemployment rates.

\section{Review and context}

Historically, economic growth and development have been key determinants of fertility decline (Herzer, Strulik, and Vollmer 2012; Myrskylä, Kohler, and Billari 2009), although by no means the only ones, and with coupling that is sometimes loose and variable (Bongaarts 2017). In the broadest terms, both historically and in the present, higher average incomes at the societal level are strongly associated with lower fertility rates; and this relationship recurs within the United States as well, as shown in the cross section in Figure 1. [code for this is "countries and states gdp fertility.do"] 

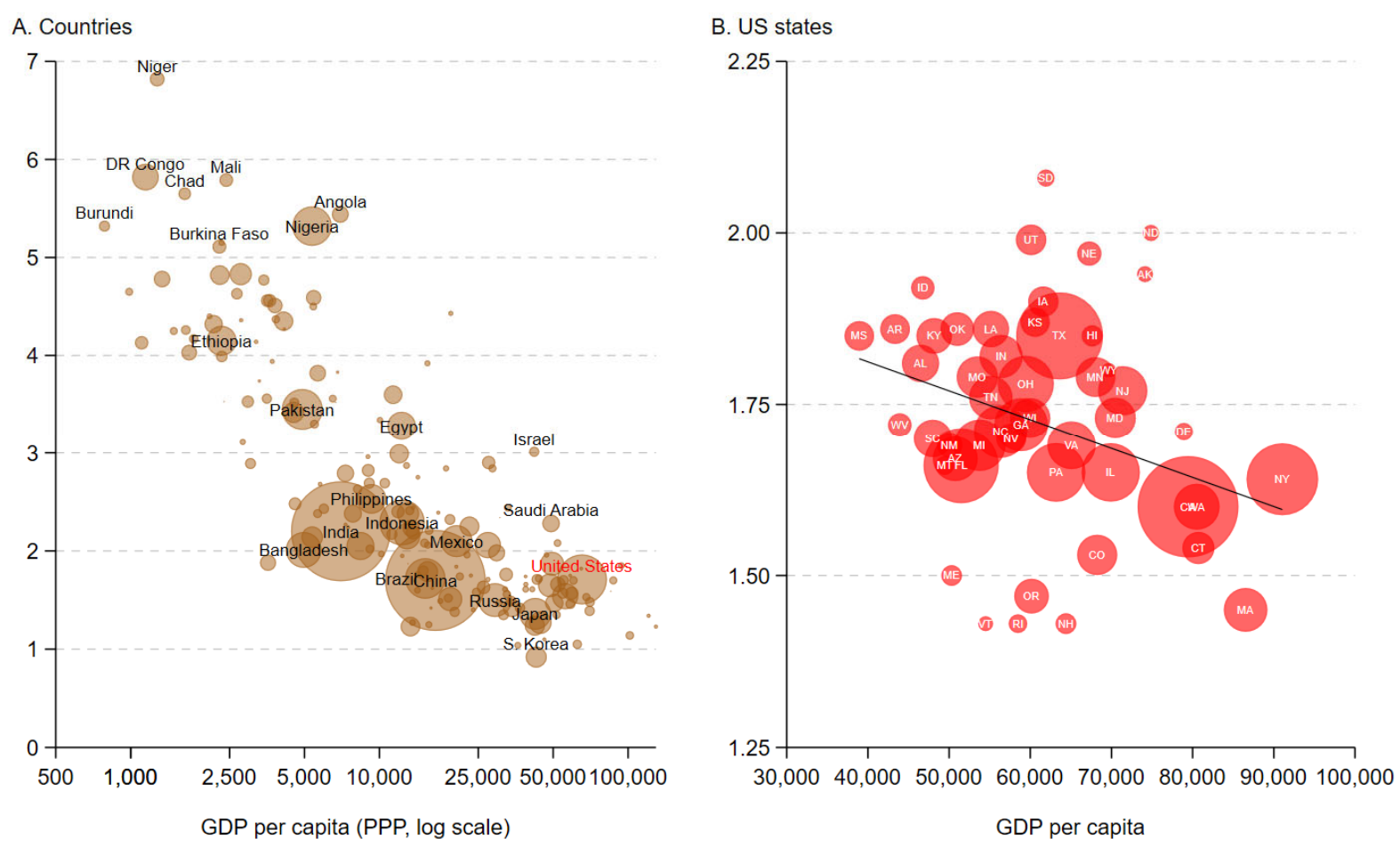

Figure 1. Total fertility rate by GDP per capita: Countries and U.S. states, 2019. Note: Markers are scaled by population. US states linear fit weighted by population. Source: World Bank, US Census Bureau, National Center for Health Statistics, Bureau of Economic Analysis.

A lower standard of living is associated with higher birth rates. However, economic crises cause declines in fertility (Currie and Schwandt 2014), and this was especially true around the 2008 recession in the U.S. (Comolli 2017; Schneider 2015) and other high-income countries (Gaddy 2021). The crisis interrupted what had been a mild recovery from falling total fertility rates in highincome countries, leading to a decline from 1.74 in 2008 to 1.57 by 2019 (Figure 2). 


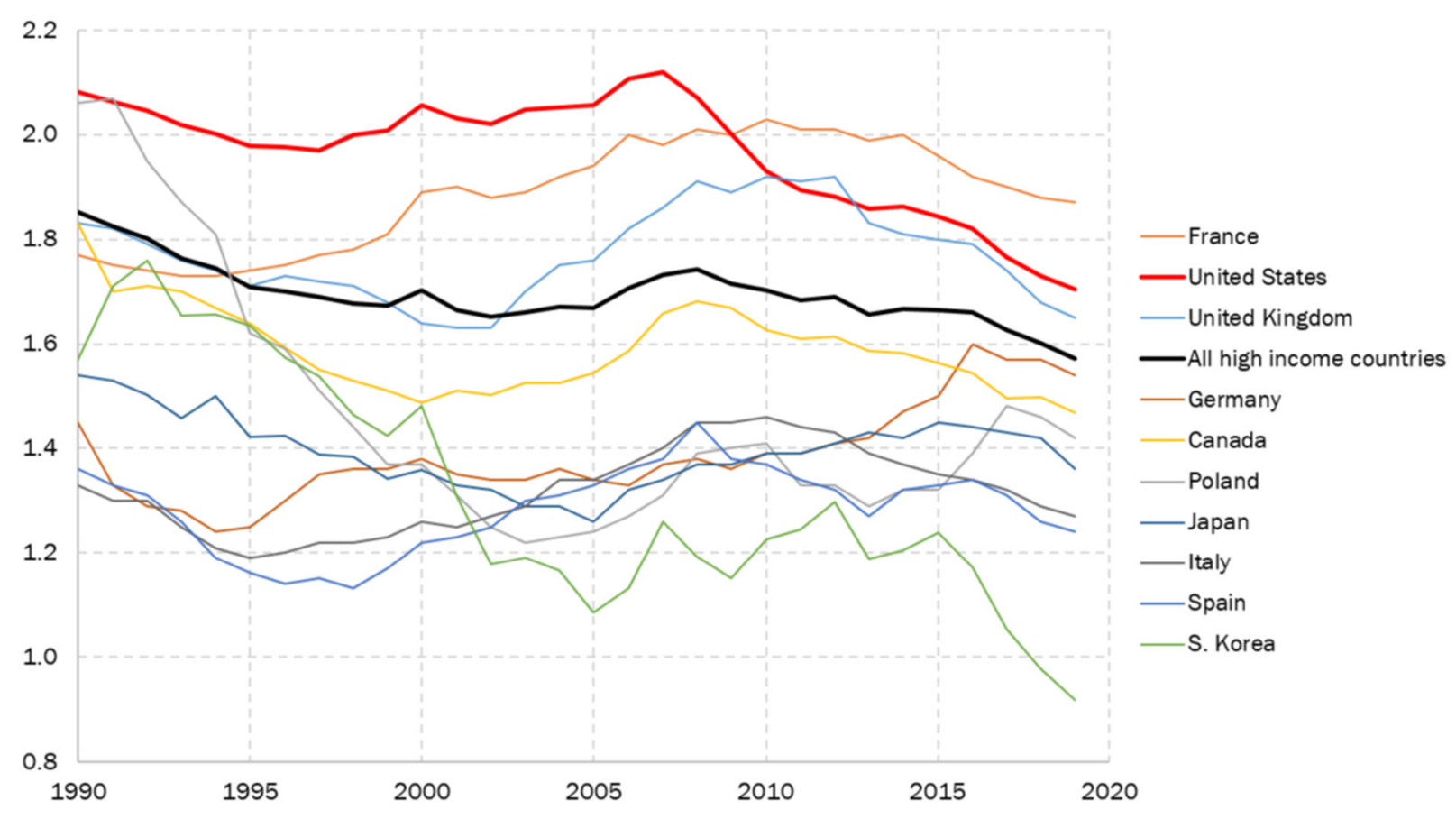

Figure 2. Total fertility rate in the 10 largest high-income countries: 1990-2019. Note: Countries with at least $\$ 30,000$ GDP per capita at PPP. Source: World Bank.

Figure 2 shows that the pattern of a peak around 2008 followed by a lasting decline is widespread (with the notable exceptions of Germany and Japan, whose TFRs were already very low), although the post-crisis decline was much steeper in the U.S. than in most other high income countries. Figure 3 puts the post-crisis TFR decline in global context, showing the change in TFR between the highest point in 2007-2009 and the lowest point in 2017-2019 for each country, by GDP per capita. (For example, the U.S. had a TFR peak of 2.12 in 2007, and its lowest point in 2017-2019 was 1.71 in 2019 , so its score is -.41.) Fertility decline is positively associated with per capita income, as lowincome countries continued the TFR declines they were experiencing before the crisis. However, among the high-income countries the relationship reversed (the inflection point in Panel $A$ is $\$ 36,600$, not shown). Thus, the sharp drop in fertility in the U.S. after the 2008 economic crisis is indicative of a larger pattern of post-crisis fertility trends. Globally, fertility is higher but falling in lower-income countries; fertility is lower in high-income counties, but fell further during the recent period of economic hardship or uncertainty. As a result of falling at both low and high ends of the economic scale, therefore, global TFR declined from 2.57 in 2007 to 2.40 in 2019 (by these World Bank data). 

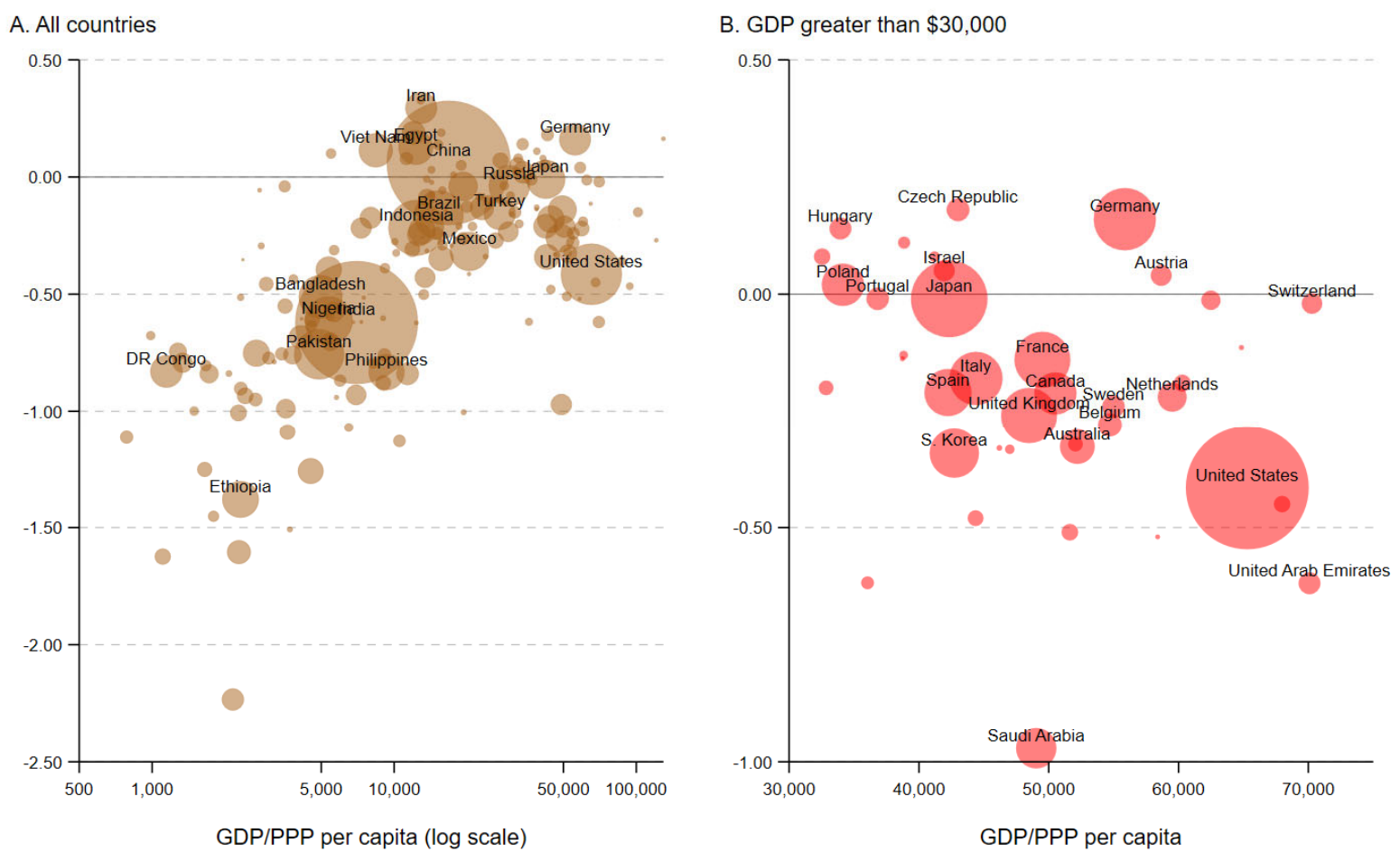

Figure 3. Difference in total fertility rate between the highest point in 2007-2009 and the lowest point in 20172019, by GDP per capita. Note: Markers scaled by population; largest countries labeled. Source: World Bank.

The mechanisms for these relationships - higher standard of living and rising unemployment both lead to lower fertility - defy simple characterization. The social scale (individual to global) may condition the relationship; there may be different effects of relative versus absolute economic wellbeing (long term and short term); development effects may be nonlinear (Myrskylä, Kohler, and Billari 2009); and the individual or cultural perception of these social facts is important as well (Brauner-Otto and Geist 2018). Note also that, as fertility rates fall with development, the question of having no children versus fewer has emerged as a more important distinction, which further complicates the interpretation of TFR trends (Hartnett and Gemmill 2020).

\section{U.S. recessions}

In the case of recent U.S. recessions, the negative impact on fertility was largest for young women. After the 2001 recession, birth rates only fell for women under age 25 . In the wake of the more severe 2008 economic crisis, birth rates fell for all ages of women up to age 40 (above which rates continued to increase every year until 2020) although the drop was still steepest below age 25 
(Cohen 2018). For the youngest women, births have continued to fall every year since, while those over age 35 saw some rebound from 2012 to 2019 (Figure 4). Clearly, during this period many women postponed births from their teens or twenties into their thirties and forties. The extent to which they will end up with lower fertility on a cohort basis depends on how late they continue (or begin) bearing children (Beaujouan 2020).

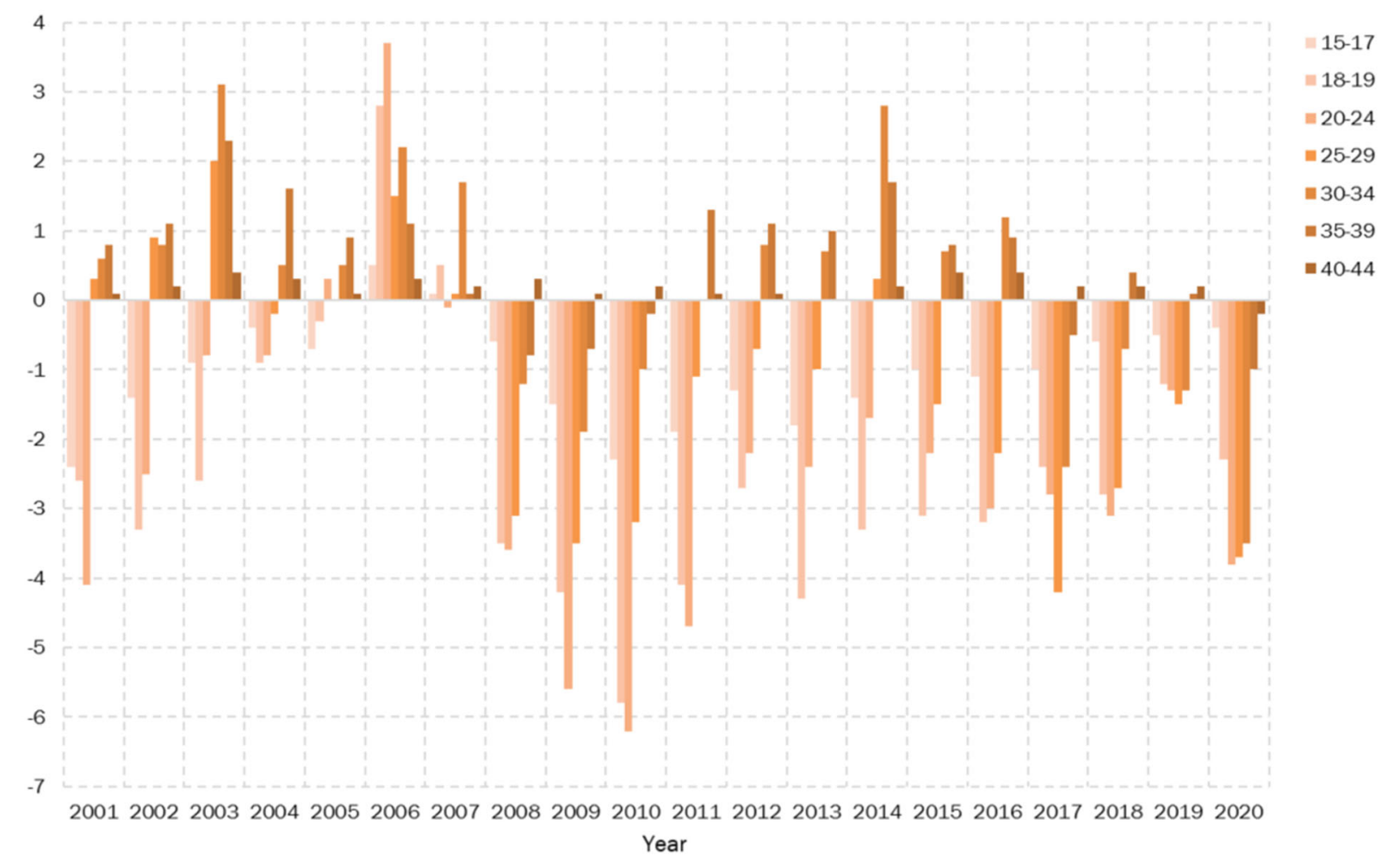

Figure 4. Annual change in U.S. births per 1,000 women, by age: 2001-2020. Source: National Center for Health Statistics.

Contrary to the suggestion that fertility decline is chiefly the result of improving opportunities for women, the pattern of delaying births is consistent with evidence that structural changes in the economy, the decline in goods-producing industries and the rise of less secure and predictable service industry jobs, are largely responsible for the lack of a fertility rebound after the 2008 recession, especially for Black and Hispanic women (Seltzer 2019). Lower education is also associated with greater uncertainty about having children among young people (Brauner-Otto and Geist 2018). For women in more precarious circumstances, especially those who are not married, these influences may be observed in the effect of unemployment rates on birth rates at the state level (Schneider and Hastings 2015). The available evidence supports the conclusion that the 2008 recession produced a large drop in fertility that did not recover before 2020 at least in part because 
the economic uncertainty it amplified has not receded - making it both a short-term and long-term event.

Birth rates recovered some for older women, however - over 30 or so - which is consistent with fertility delay. But this delay does not necessarily favor the opportunity cost versus economic constraint explanations. On one hand are people with higher levels of education (anticipated or realized) who plan to wait until their education is complete. On the other hand are those with less education who are most economically insecure, whose delays reflect navigating the challenges of relationship instability, housing, health care, childcare and other costs with lesser earning potential. This latter group may end up delaying either until they attain more security or until they face the prospect of running out of childbearing years. Both groups are deliberately delaying births partly for economic reasons, but the higher-education group is much more likely to have planned births while the latter have higher rates of unintended or mistimed births (Hayford and Guzzo 2016).

The opportunity cost of women's childbearing, in classical models, is simply the earnings lost from time spent childrearing - the product of the hours of employment lost and the expected hourly wage (Cramer 1979). Although rising income potential for women has surely contributed to the long-run decline of fertility rates, in the U.S. that mechanism has not been determinative. Women experienced large increases in earnings for decades during which fertility rates did not fall. As the total fertility rate rose from its low point in 1976 (1.74) to the post-Baby Boom peak in 2007 (2.12) - defying the trend in many other high-income countries - the average weekly earnings of full-time working women ages $18-44$ rose by $16 \%$ in constant dollars (Figure 5). 


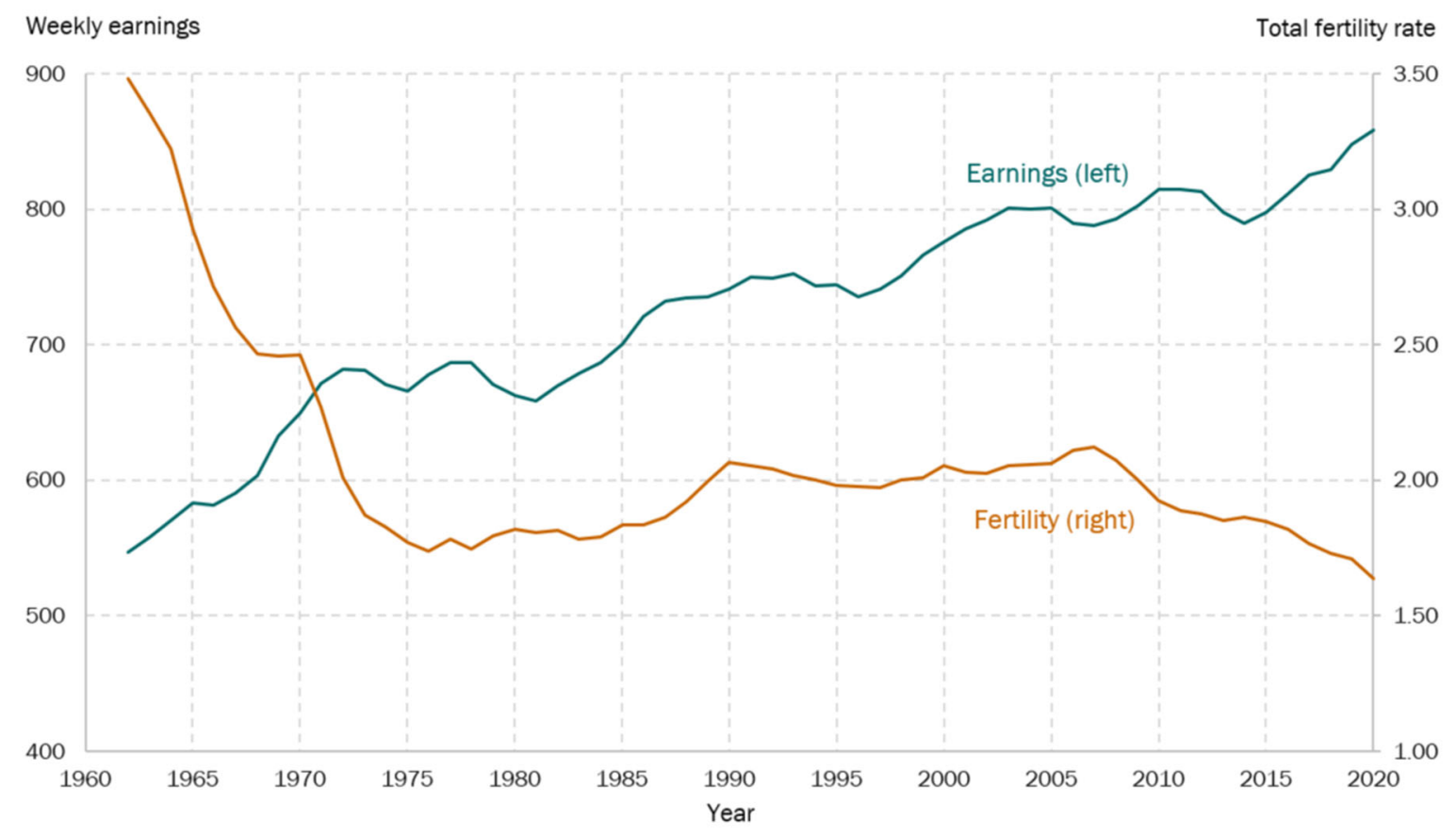

Figure 5. Median weekly earnings of full-time employed women ages 18-44, and total fertility rate. Source: Current Population Survey Annual Social and Economic Survey, and Human Fertility Database.

Clearly, other factors beyond lost earnings calculations are at work. However, there is no simple way to distinguish those who make direct cost comparisons, where investments in time and money take away from other needs and opportunities, from those who delay out of concern over future economic security, which weighs on people at all income levels and generates reluctance to make lifelong commitments (Pugh 2015). But the implications of these two effects are opposing. For people who don't want to lose opportunities, a strong economy with abundant jobs implies lower fertility. For people who are afraid to commit to childrearing because of insecurity about their economic fortunes, a weak economy should decrease fertility. The experience of the post-2008 period provides strong evidence for the greater weight of the latter mechanism.

\section{US births, 2000-2019}

If opportunity costs were the primary consideration for women, one might expect an inverse relationship between job market growth and fertility rates: more jobs, fewer babies; fewer jobs, more babies. This is the pattern reported by Tavernise et al. (2021), who found that birthrates after the 2008 crisis fell more in counties with "growing labor markets" - which they attribute to the combination of improving opportunities for women and the high costs of childcare. However, their analysis did not attend to chronological ordering. They identified counties as having strong job 
growth if they were in the top quintile of counties for labor market percent change for the period 2007 to 2019 , and compared them with counties in the bottom quintile of counties on the same measure with regard to birth rates (author correspondence). Thus, their analysis used a 2007-2019 summary measure to predict birth rates for each year from 1990 to 2019 , making the results difficult to interpret.

In addition to using contemporaneous economic data, whereas Tavernise et al. (2021) used countylevel birth rates, in this analysis I use individual characteristics and state-level data. I construct indicators of individual- and state-level relative advantage during the period before and after the 2008 economic crisis, from 2000 to 2019. Individual data are from the 2000-2019 American Community Survey (ACS) via IPUMS (Ruggles et al. 2021). I include in the analysis women ages 1544 , and use the fertility question, which asks whether they had a baby in the previous 12 months. I analyze this as a dichotomous dependent variable, using ordinary least squares regression. Results are graphed as marginal effects at the means, using Stata's margins command. The sample size is $9,415,960$ million women, 605,150 (6.4\%) of whom had a baby in the previous year (multiple births are counted only once).

In models with controls, I control for age in five-year bins, race/ethnicity (White, Black, American Indian, Asian/Pacific Islander, Other/multiple-race, and Hispanic), citizenship (U.S.-born, born abroad to American parents, naturalized, and not a citizen), marital status (married, spouse absent, separated, divorced, widowed, and never married), education (less than high school, high school graduate, some college, and BA or higher degree), as well as (in some models) the state unemployment rate (lagged two years), and state fixed effects. State unemployment rates are from Local Area Unemployment Statistics (Bureau of Labor Statistics 2021). ACS person weights are used in all analyses.

For states, I use the unemployment rate in each state for each year, and divide the states at the median, so those with the median or higher unemployment for each year are coded as high unemployment states, and low unemployment otherwise (this variable is lagged two years, because the ACS asks whether each woman has had a birth in the previous 12 months, but does not specify the month of the birth, or the date of the interview). For individuals, the identification of economic advantage is difficult with the cross-sectional data I use here, because incomes are likely to fall in the year of a birth, and education may be determined endogenously with fertility as women age (Hartnett and Gemmill 2020), so income and education cannot simply be used to identify economic status. Instead, I identify women as low education if they have less than the median level of education for women of their age in their state for each year (using single years of age, and 26 
categories of educational attainment), and high education otherwise. Thus, individual women in my sample are coded as in a high or low unemployment state relative to the rest of the country each year, and as having high or low education relative other women of their age and state and year. Using the ACS migration variable, I code women into the state they lived in the previous year, which is more likely to identify where they lived when they determined whether to have a baby (which also means I exclude women who were not living in the U.S. in the year before the survey).

Figure 6 shows the unadjusted probability of birth for women in high- and low-unemployment states for the period 2000-2019. This shows the drop in birth rates after 2008, which is steeper for women who live in high-unemployment states, especially before 2017. This is what we would expect from previous research on the 2008 financial crisis: a greater falloff in birth rates where the economy suffered more.

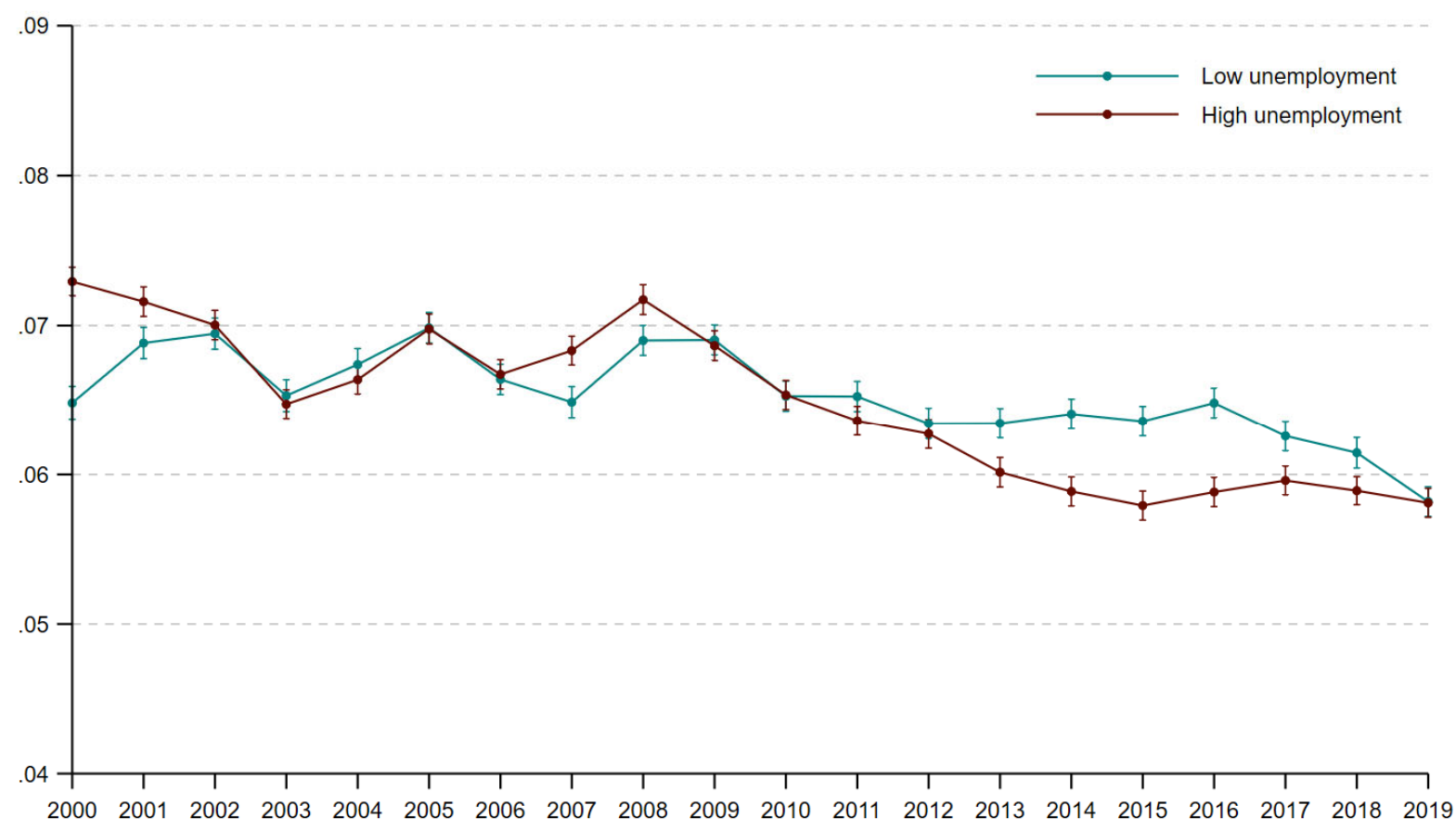

Figure 6. Probability of birth in the previous year: $2000-2019$, by state unemployment relative to the national media (marginal effects at the means). Women ages 15-44. Based on state of residence in the previous year; unemployment lagged two years.

Next, I split the sample again by women's own education relative to the median for those of the same age, year, and state. Those less than that median are coded as low education, those at or higher than the median are coded as high education. Figure 7 shows these results (again, unadjusted for control variables), showing that those with lower education (the top two lines) have higher birth rates throughout the period. After 2008, within both the high- and low-education groups, 
those in high-unemployment states had longer and steeper declines in birth rates (at least until 2019). The steepest decline is among low-education, high-unemployment women: those facing the greatest economic hardship at both the individual and state level. Finally, Figure 8 repeats the model shown in Figure 7, but with the control variables described above, and with state fixed effects. The pattern is very similar, but the differences associated with state unemployment are attenuated, especially for those with low education.

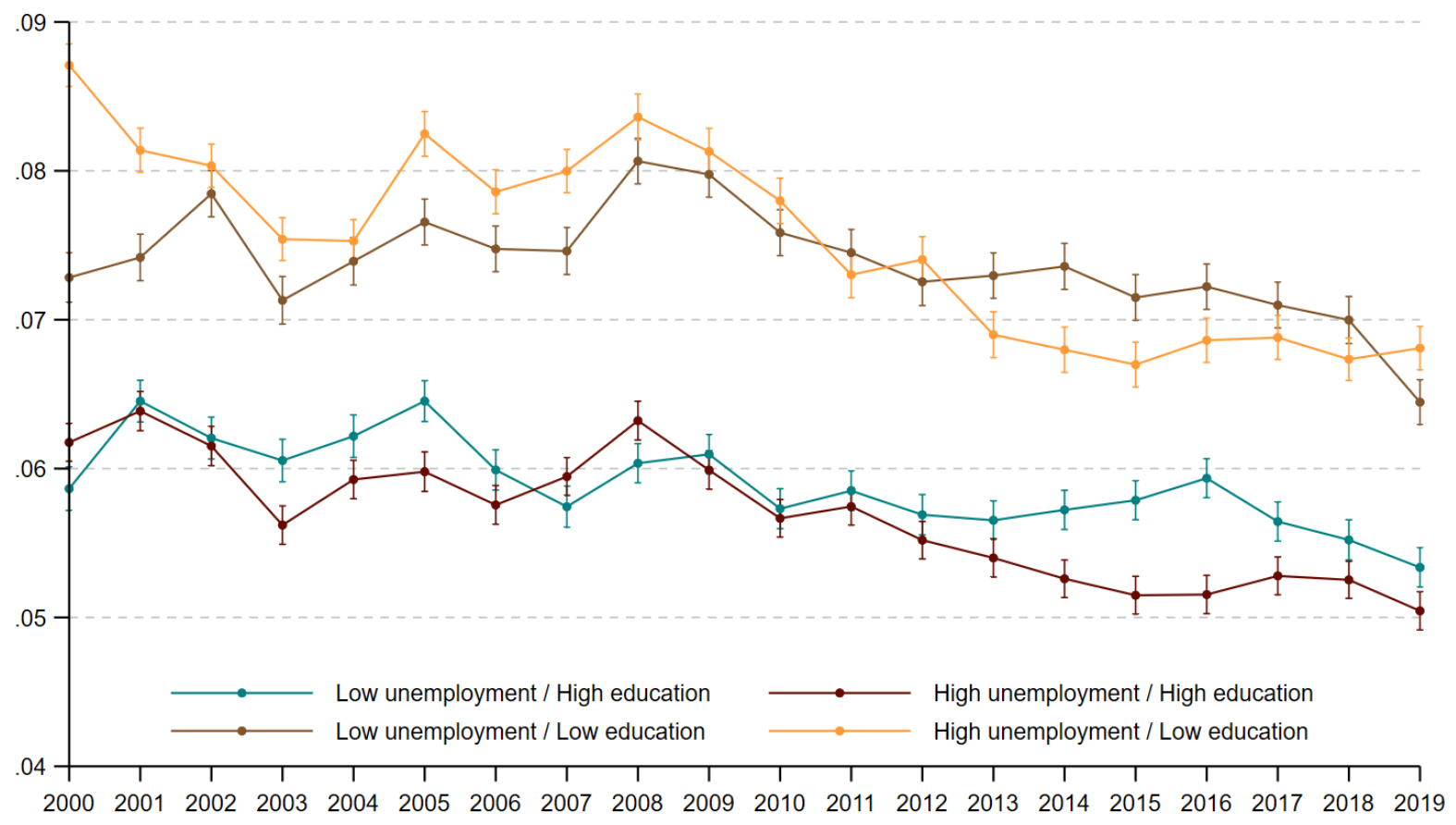

Figure 7. Probability of birth in the previous year: $2000-2019$, by education relative to the age-state median, and state unemployment relative to the national media (marginal effects at the means). Women ages 15-44. Based on state of residence in the previous year; unemployment lagged two years. 


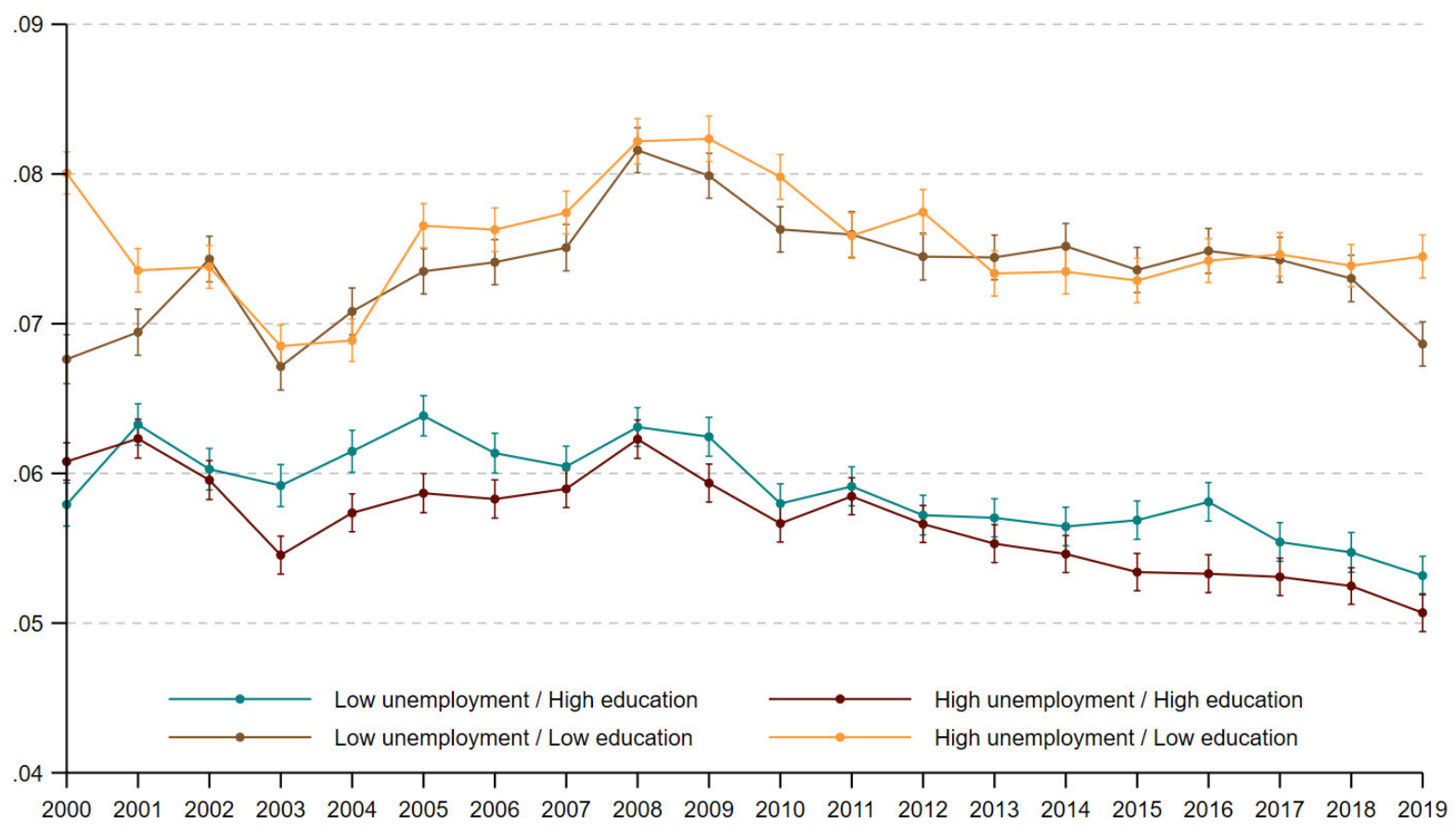

Figure 8. Probability of birth in the previous year: $2000-2019$, by education relative to the age-state median, and state unemployment relative to the national media, with controls for age, race/ethnicity, citizenship, marital status, and state fixed effects (marginal effects at the means). Women ages 15-44. Based on state of residence in the previous year; unemployment lagged two years.

\section{Discussion}

Although birth rates fell for all four groups of women in this analysis after the 2008 recession, these results reflect that paradoxical nature of economic trends and birth rates. Women with higher education (and greater potential earnings) have lower birthrates, consistent with the opportunity cost reasoning described in Tavernise et al. (2021) and elsewhere. However, women in states with higher unemployment rates - especially when they have high relative education - also have lower birthrates, and in these states saw greater declines after the 2008 crisis. This is consistent with the evidence of negative effects of economic uncertainty and stress. And it goes against the suggestion that stronger job markets drive down fertility rates for women with higher earning potential, at least in the post-2008 period. In the long run, perhaps, economic opportunities reduce childbearing by increasing job market opportunities for potential mothers, but in recent years this effect has been swamped by the downward pressure of economic troubles. US birth rates fell further in 2020 , apparently driven down by the COVID-19 pandemic, which raised uncertainty - and fear for the future - to new heights (Cohen 2021; Sobotka et al. 2021). We don't yet know the breakdown of the 
shifts in fertility for that year, but if the effects were similar to those of the 2008 economic crisis, we would expect to see greater declines among those who were most vulnerable.

\section{References}

Beaujouan, Eva. 2020. "Latest-Late Fertility? Decline and Resurgence of Late Parenthood Across the Low-Fertility Countries." Population and Development Review 46 (2): 219-47. https://doi.org/10.1111/padr.12334.

Bongaarts, John. 2017. "Africa's Unique Fertility Transition." Population and Development Review 43 (S1): 39-58. https://doi.org/10.1111/j.1728-4457.2016.00164.x.

Brauner-Otto, Sarah R., and Claudia Geist. 2018. "Uncertainty, Doubts, and Delays: Economic Circumstances and Childbearing Expectations Among Emerging Adults." Journal of Family and Economic Issues 39 (1): 88-102. https://doi.org/10.1007/s10834-017-9548-1.

Bureau of Labor Statistics. 2021. "States and Selected Areas: Employment Status of the Civilian Noninstitutional Population, January 1976 to Date, Seasonally Adjusted." 2021. https://www.bls.gov/web/laus/ststdsadata.txt.

Cohen, Philip N. 2018. Enduring Bonds: Inequality, Marriage, Parenting, and Everything Else That Makes Families Great and Terrible. Oakland, California: University of California Press.

—. 2021. "Baby Bust: Falling Fertility in US Counties Is Associated with COVID-19 Prevalence and Mobility Reductions." SocArXiv. https://doi.org/10.31235/osf.io/qwxz3.

Comolli, Chiara Ludovica. 2017. "The Fertility Response to the Great Recession in Europe and the United States: Structural Economic Conditions and Perceived Economic Uncertainty." Demographic Research 36 (51): 1549-1600. https://doi.org/10.4054/DemRes.2017.36.51.

Cramer, James C. 1979. "Employment Trends Ofyoung Mothers and the Opportunity Cost of Babies in the United States." Demography 16 (2): 177-97. https://doi.org/10.2307/2061137.

Currie, Janet, and Hannes Schwandt. 2014. "Short- and Long-Term Effects of Unemployment on Fertility." Proceedings of the National Academy of Sciences 111 (41): 14734-39. https://doi.org/10.1073/pnas.1408975111.

Filipovic, Jill. 2021. "Opinion | Women Are Having Fewer Babies Because They Have More Choices." The New York Times, June 27, 2021, sec. Opinion. https://www.nytimes.com/2021/06/27/opinion/falling-birthrate-women-babies.html.

Gaddy, Hampton Gray. 2021. "A Decade of TFR Declines Suggests No Relationship between Development and Sub-Replacement Fertility Rebounds." Demographic Research 44 (5): 125-42. https://doi.org/10.4054/DemRes.2021.44.5.

Hartnett, Caroline Sten, and Alison Gemmill. 2020. "Recent Trends in U.S. Childbearing Intentions." Demography 57 (6): 2035-45. https://doi.org/10.1007/s13524-020-00929-w.

Hayford, Sarah R., and Karen Benjamin Guzzo. 2016. "Fifty Years of Unintended Births: Education Gradients in Unintended Fertility in the US, 1960-2013." Population and Development Review 42 (2): 313-41.

Herzer, Dierk, Holger Strulik, and Sebastian Vollmer. 2012. "The Long-Run Determinants of Fertility: One Century of Demographic Change 1900-1999.” Journal of Economic Growth 17 (4): 357-85. https://doi.org/10.1007/s10887-012-9085-6.

Myrskylä, Mikko, Hans-Peter Kohler, and Francesco C. Billari. 2009. "Advances in Development Reverse Fertility Declines." Nature 460 (7256): 741-43. https://doi.org/10.1038/nature08230.

Pugh, Allison J. 2015. The Tumbleweed Society: Working and Caring in an Age of Insecurity. 1 edition. New York, NY: Oxford University Press. 
Ruggles, Steven, Sarah Flood, Sophia Foster, Ronald Goeken, Jose Pacas, Megan Schouweiler, and Matthew Sobek. 2021. "IPUMS USA: Version 11.0 [Dataset]." 2021. doi.org/10.18128/D010.V11.0.

Schneider, Daniel. 2015. "The Great Recession, Fertility, and Uncertainty: Evidence From the United States." Journal of Marriage and Family 77 (5): 1144-56. https://doi.org/10.1111/jomf.12212.

Schneider, Daniel, and Orestes P. Hastings. 2015. "Socioeconomic Variation in the Effect of Economic Conditions on Marriage and Nonmarital Fertility in the United States: Evidence From the Great Recession." Demography 52 (6): 1893-1915. https://doi.org/10.1007/s13524-015-0437-7.

Seltzer, Nathan. 2019. "Beyond the Great Recession: Labor Market Polarization and Ongoing Fertility Decline in the United States." Demography 56 (4): 1463-93. https://doi.org/10.1007/s13524-019-00790-6.

Sobotka, Tomas, Aiva Jasilioniene, Ainhoa Alustiza Galarza, Kryštof Zeman, Laszlo Nemeth, and Dmitri Jdanov. 2021. "Baby Bust in the Wake of the COVID-19 Pandemic? First Results from the New STFF Data Series." SocArXiv. https://doi.org/10.31235/osf.io/mvy62.

Tavernise, Sabrina, Claire Cain Miller, Quoctrung Bui, and Robert Gebeloff. 2021. "Why American Women Everywhere Are Delaying Motherhood." The New York Times, June 16, 2021, sec. U.S. https://www.nytimes.com/2021/06/16/us/declining-birthrate-motherhood.html. 